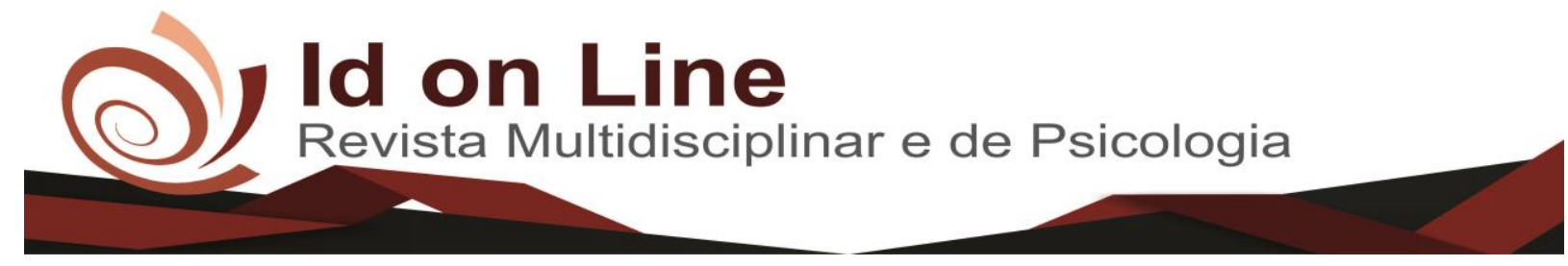

Comment

\title{
O Departamento de Estoque como fator influenciador na Gestão de Empresas
}

\author{
Karina Akemi ${ }^{l}$; Mariana Emídio Oliveira Ribeiro ${ }^{2}$; \\ Anna Ariane Araújo de Lavor ${ }^{3}$; Antônio Carlos Alves da Silva ${ }^{4}$
}

\begin{abstract}
Resumo: O presente trabalho, teve como objetivo verificar como a gestão de estoque influencia nas empresas, visto que ter um estoque é essencial para as organizações, uma vez que auxilia no processo de vendas e na garantia aos clientes. A metodologia utilizada foi a de pesquisa bibliográfica, com leituras, comentários e citações por meio de livros e sites especializados. Utilizou-se a pesquisa qualitativa, cujoa hipótese da pesquisa não obteve uma resposta de sim ou não, e também exploratória, que tem como objetivo alcançar novas percepções do assunto e descobrir novas ideias. Essa pesquisa foi realizada no segundo semestre de 2016. Os resultados obtidos explicam que é fundamental um estoque nas empresas, pois torna-se eficiente ao atender melhor os clientes, no qual, se torna apta a competir com as outras empresas do mesmo segmento. O estoque é um dos principais departamentos dentro de uma empresa, é nele que é armazenado todos os produtos que são vendidos. E há sempre uma pessoa responsável por ele, que organiza e faz os controles diariamente para que assim o estoque e os produtos que nele é composto fiquem em ordem. Funcionários de depósito são os responsáveis por fazer todo o inventário com a função de controlar o estoque. Onde é necessário sempre fazer a contagem dos produtos, ou até mesmo um balanço a cada três meses para verificar se a contagem no estoque físico confere com a do contábil. Desse modo, é fundamental para as empresas e até mesmo para a comodidade dos clientes e funcionários a obtenção de um estoque de materiais, pois além do estoque ser uma estratégia para as empresas, onde em muitos casos o lucro é evidente, o mesmo também serve para ter produtos sempre disponíveis para as vendas, sendo assim, uma das funções indispensável dentro de qualquer organização.
\end{abstract}

Palavras-chave: Administração, Empresas, Estoque, Produtos.

\section{The Stock Department as an influencing factor in Business Management}

\begin{abstract}
The present work had as objective to verify how the stock management influences in the companies, since having a stock is essential for the organizations, since it assists in the process of sales and the guarantee to the clients. The methodology used was the one of bibliographical research, with readings, commentaries and citations through books and specialized websites. The qualitative research was used, whose research hypothesis did not obtain a yes or no answer, and also an exploratory one, that aims to reach new perceptions of the subject and to discover new ideas. This research was carried out in the second half of 2016. The obtained results explain that a stock in the companies is fundamental, because it becomes efficient when better serving the clients, in which, it becomes apt to compete with the other companies of the same segment. Stock is one of the main departments within a company, it is in it that all the products that are sold are stored. And there is always a person responsible for it, who organizes and controls daily so that the stock and the products in it are in order. Depositors are responsible for doing all inventory with the stock control function. Where it is necessary to always do the counting of the products, or even a balance every three months to verify if the count in the physical stock confers with that of the accounting. In this way, it is fundamental for companies and even for the convenience of customers and employees to obtain a stock of materials, since in addition to inventory it is a strategy for companies, where in many cases profit is evident, it also serves To have products always available for sales, thus being one of the indispensable functions within any organization.
\end{abstract}

Key-Words: Administration, Companies, Stocks, Products.

\footnotetext{
${ }^{1}$ Graduanda em Administração pela Faculdade de Alta Floresta FAF. Contato: madrid.karina@outlook.com;

${ }^{2}$ Mestranda em Ambiente e Desenvolvimento pala UNIVATES. Contato: mariana_meo@ hotmail.com;

${ }^{3}$ Mestranda em Ambiente e Desenvolvimento pala UNIVATES. Contato: annaariane@ hotmail.com;

${ }^{4}$ Mestrando em Ambiente e Desenvolvimento pala UNIVATES. Contato: acas-acas@ @otmail.com;

16 Id on Line Rev. Mult. Psic. V.11, N. 38. 2017 - ISSN 1981-1179

Edição eletrônica em http://idonline.emnuvens.com.br/id
} 


\section{Introdução}

O tema proposto é discutido desde a década de 50, visto que em termos de tempo a gestão de estoque vem sendo abordada ao longo de toda a geração primordial do homem, sendo para garantir a alimentação por um certo período de tempo ou para a gestão de uma empresa como forma de investimento. No entanto, é necessário observar e ficar atento as mudanças globais e ao fluxo de consumidores, pois a partir do momento em que houver uma redução nas vendas, ocorrerá também uma diminuição nas compras.

As empresas atualmente, possuem um estoque significativamente de acordo com o porte de cada uma ou conforme o volume da mercadoria. Porém, diversas delas ainda não adotaram o método de estocagem dos produtos, mas buscam constatemente manter um estoque adequado para obter vantagens competitivas no mercado. Sendo assim, é necessário ter o conhecimento no ato da compra para evitar excessos de produtos ou até mesmo desnecessários ou que poderão tornar-se obsoletos.

Hoje, na gerência das empresas, tem se dado uma maior importância em garantir que o cliente saia satisfeito e com o produto em mãos, além do estoque ser um departamento essencial, torna-o flexível entre as empresas da mesma área. Porém, se houver uma defiência no controle do estoque isso poderá sofrer prejuizos futuros dentro da empresa, como por exemplo, atrasar as entregas dos clientes, que dessa forma faz com que as empresas possam correr o risco de perder o cliente para uma empresa do mesmo ramo.

Entretanto, é fundamental ter flexibilidade em qualquer área dentro da empresa, para chegar a excelência e conquistar a clientela. Dentro de uma organização há setores que são responsáveis por cada etapa que ocorre, desde a entrada de um produto até o processo de venda do mesmo. A princípio vem a questão dos suprimentos, onde entra o processo das compras, que devem ser feitos com cautela e experiência. Sempre é bom pensar em quantidade e qualidade, duas palavras que devem permanecer juntas. Muitas vezes compramse determinados produtos em quantidades muito maiores, para que assim possa se beneficiar na redução do preço unitário.

Os benefícios que este estudo pode proporcionar às empresas são, maior clareza sobre se de fato é vantajoso possuir um estoque, qual o nível da importância do estoque e sua satisfação em relação a venda e a mercadoria. Os erros no momento da formação de um 
estoque são evidentes, aos olhos de quem a gerência. Dessa maneira, é mais fácil e simples verificar que a maioria das empresas possuem dificuldades em trabalhar com os estoques.Geralmente, diversas delas saem no prejuízo por ausência de conhecimento, inclusive de gestores incapazes ou inexperientes. Assim, é primordial hoje, os gestores especializar-se em cursos de Gestão de Estoque ou também, realizar um estudo a respeito da empresa, no qual, exercerá a correspondente tarefa.Acredita-se que no Brasil há cerca de 17 bilhões de empresas ativas no mercado de vários ramos diferentes, havendo aquelas em que necessitam de um estoque, como os mercados, e outras que não, o que é perfeitamente comum. Porém, o número de pessoal qualificado ainda é pequeno,se comparar com a quantidade de empresas ativas. Mas este trabalho visa demonstrar o quão é importante um estoque e mostrar recursos, métodos e vantagens mais relevantes que uma organização leva a constituir um estoque.

Diante disso, levantou-se o seguinte questionamento: Com as constantes mudanças no mercado, quais os benefícios do controle de estoques para as empresas?

Os estoques em sua maioria possuem uma importância eficiente dentro das empresas; os estoques tem uma finalidade prática, comprando-se os mesmos em preços mais baixos e vendendo por mais altos; as empresas, tem como recurso o poder de barganha; os vendedores das empresas se sentem motivados a venderem mais, por terem o produto na loja; os Gestores de Estoques procuram se aperfeiçoar e tornar-se eficiente no controle dos estoques; para os clientes, as empresas que garantem o produto a pronta entrega é de suma importância.

Os objetivos que nortearam a pesquisa foram: verificar a importância da função do estoque para as empresas; verificar quais as vantagens competitivas e o impacto que causa o estoque nas empresas; verificar quais os principais custos de um estoque das empresas.

O intuito deste estudo foi oferecer aos empresários formas de administrar um estoque, efetivar os prazos de entrega, no qual, aumenta a confiança dos consumidores, incentivo para que as empresas se atualizem e se profissionalizem na área do estoque, mostrando a importância do mesmo por meio deste trabalho, e contribuindo para o melhoramento das empresas no mercado e diante dos concorrentes.Explica também, as consequências causadas pela falta de estoque e o impacto que causa os estoques nas empresas, no qual, são assuntos de suma importância. 


\section{Embasamento Teórico}

Segundo Martins e Alt (2009) o conhecimento dos estoques das empresas é tão antigo quanto a administração. Assim como, um processo produtivo que no final da cadeia de suprimentos criará algum vínculo para o consumidor final, o estoque é primordial e é um dos setores mais importante dentro de uma empresa. As empresas, atualmente, buscam sempre manter vantagens em relação ao consumidor e aos seus concorrentes, com um estoque atualizado é possível atender uma demanda vasto de clientes, no momento e na quantidade desejada. Aliás, os estoques também servem para as negociações de preços com os fornecedores, muitas vezes, há promoções em compras de grandes quantidades, o que se torna um benefício para as empresas.

Antigamente, a relação cliente-fornecedor era divergente aos dias de hoje. Antes, cada um buscava tirar vantagens de algum modo e se tratavam como se fossem inimigos, do contrário, atualmente, as empresas têm um vínculo de parceria com os fornecedores, buscam sempre manter uma solução para os problemas e benefícios para os clientes.

Porém, a importância do estoque dentro das empresas é formada pela citação de Iudicibus, Martins e Gelbcke (2000, p. 101):

\footnotetext{
Os estoques representam um dos ativos mais importantes do capital circulante e da posição financeira da maioria das companhias industriais e comerciais. Sua correta determinação no início e no fim do período contábil é essencial para uma apuração adequada do lucro líquido do exercício. Os estoques estão intimamente ligados às principais áreas de operação dessas companhias e envolvem problemas de administração, controle, contabilização e principalmente de avaliação (IUDICIBUS; MARTINS; GELBCKE, 2000, p. 101).
}

Isso demonstra o quanto ter um estoque e saber controla-lo é essencial dentro de qualquer organização. Paura (2012) também explica que a administração de materiais é de suma importância para as empresas, uma vez que, consegue ter o produto disponível a qualquer momento, tendo como exemplo, uma indústria que está fabricando um produto, no qual, em um momento inesperadoocorre a ausência da peça no estoque, isso significa que a produção será interrompida até a peça desejada chegar. Da mesma forma, acontece com os clientes das empresas, que vão as lojas comprar determinado produto e que de preferência seja entregue o mais rápido possível. 
Já na visão de Ballou apud Martins e Alt (2009, p. 171) os estoques têm como benefícios são:

1. o serviço ao cliente: dando suporte e tendo o produto a pronta entrega;

2. economia de escala: os custos são menores quando comprados produtos em grandes quantidades;

3. vantagens contra incertezas na demanda e no tempo de entrega: isso significa que caso aja a possibilidade do fornecedor atrasar com os produtos, a garantia do produto estar em mãos do cliente é maior, pois haverá no estoque;

4. vantagensnas mudanças de preços: uma alta compra de produtos, minimiza o aumento de preços, pois, o estoque antigo comprado por preços antigos, vai ter uma vantagens na hora de elaborar o preço de venda;

5. vantagensna possibilidade de imprevistos: no caso de algum fornecedorentrar em férias coletivas ou em greve e a empresa ficar sem o produto para atender aos clientes, isso não vai ocorrer, por causa do estoque.

A importância do estoque também é exposta na seguinte citação de Paura:

Essa facilidade do estoque traz vantagem competitiva para as empresa, pois agrega valor ao produto. Uma vez que a empresa tenha o produto a disposição do cliente em um menor tempo, em relação aos seus concorrentes, pode levar o consumidor a optar por pagar um pouco mais para ter o produto em menor tempo (PAURA, 2012, p. 40).

Atender aos clientes no momento certo e na quantidade desejada tem sidouma das principais vantagens, assim como a rapidez e a qualidade na prestação dos serviços declaracada vez mais uma vantagem competitiva no mercado.

Conforme Pozo (2004) ter um estoque está relacionado com a prevenção de momentos futuros inesperados. É difícil saber qual será a demanda futura, o que se torna obrigatório determinar um nível de estoque, para proporcionar aos clientes a disponibilidade dos produtos, assim como minimizar os custos de produção, movimentação e estoques.

De acordo com Gonçalves (2010), o estoque é uma aplicação que abrange o envolvimento de recursos que poderiam ser utilizados em outros setores das empresas, porém, a existência dele é vital para o funcionamento das mesmas. O autor ainda afirma que de acordo com os aspectos financeiros, o estoque possui um custo de capital, que por sua vez imobiliza ativos financeiros, mas por outro lado, possuir estoque pode representar uma vantagem caso o empresário esteja inserido num contexto especulativo de preços com uma 
variação elevada de preços, tornando um risco de mercado ficar dependente da aquisição de mercadorias no momento da necessidade de giro.

Se as empresas adotarem ter um estoque os custos serão de armazenamento e movimentação. Esses custos englobam os custos do espaço, das condições de armazenagem, como por exemplo, ambientes climatizados, movimentação interna, controles, perdas, produtos obsoletos, extravios, entre outros.

O autor Viana (2006) também afirma que os custos dos materiais armazenados consistem em alguns fatores, como:

a) abundância do material;

b) tempoda existência do material;

c) quantidade de serviços e operadores utilizados para que isso aconteça;

d) custos com outras despesas (água, espaço, energia, entre outros);

e) desvalorização dos produtos.

É necessário dominar a gestão de estoque, uma vez que, é induzida com tamanha intensidadenos recursos financeiros. Para que o aumento das vendas traga pontos positivos dentro das empresas exige que a mesma faça investimentos no estoque para que assim possa atender a demanda devida, afirmou também Carvalho (2015).

Para que isso ocorra de maneira eficaz Dias (2011) explica que é fundamental a competência no momento do controle de estoques, no qual, determina-se o que e quando comprar, quanto de estoque é necessário certo período de tempo, detectar os produtos com defeitos e fazer a retirada dos mesmos, receber as mercadorias e deposita-las corretamente de acordo com cada necessidade, fazer o controle de estoque e comunicar os outros colaboradores sobre o posicionamento do mesmo, informar o responsável por compras para realizar a aquisição de produtos faltosos no estoque; e conservar o balanço e o inventário frequente para a organização dos produtos em estoque.

Desta maneira, o controle de estoque é diferente em cada tipo de almoxarifado. De acordo com Pozo (2004), existem: estoques de matérias-primas que são os materiais que irá ser modificado para entrar no estoque de produtos acabados, estoques de materiais auxiliares que são ferramentas necessárias para a fabricação dos produtos, estoques de manutenção que é utilizada para o armazenamento de materiais que fazem parte da manutenção dos equipamentos e também de escritório, estoque intermediário que são aonde os produtos pré finalizados (aqueles que faltam alguma peça, que não tem no estoque de manutenção) e o 
estoque de produtos acabados que são as mercadorias que já estão fabricadas e devidamente embaladas para o processo de vendas.

Conforme Bento (2008) os estoques têm como missão exercer como um sistema equilibrado dentro das empresas. Uma vez que, o tempo do recebimento é diferente do tempo em que são utilizadas, no qual, funciona se tornam cada vez mais equilibradas.

De acordo com Viana (2006) as empresas japonesas são um exemplo na gestão de estoques, uma vez que, a sua tecnologia é a mais avançada do mundo. Apesar disso, nem sempre foi assim, após a derrota da segunda guerra mundial, o Japãocomeçou a copiar o modelo americano, visto que, a derrota na guerra foi consequência de uma gestão de estoque mal administrada, com falta de espaço e de recursos naturais. A partir daí, surge o seguinte termo da perda zero, que significa produzir sem perdas, com qualidade e um menor custo. Com base nisso, surgiu o Just in time (é um sistema que define que tudo deve ser produzido ou comprado no momento certo) e o Jidoka (que é um controle visual onde cada operador sua qualidade e sua produção mínima evitando as perdas).

\section{Metodologia}

A seguinte pesquisa teve como auxilio para a pesquisa, as bases de dados como: Periódicos, Capes Scielo e BDTD. O procedimento metodológico envolveu a pesquisa bibliográfica que: "procura explicar um problema a partir de referências teóricas publicadas em documentos" (CERVO; BERVIAN, 2002, p. 65).

A pesquisa bibliográfica pode ser explicada pela seguinte citação Manzo apud Marconi e Lakatos (2010), no qual, procura demonstrar por meio da pesquisa não somente meios de problemas conhecidos, mais busca também explorar e conhecer novos conteúdos, podendo assim, ir se aperfeiçoando ainda mais no tema discutido.

O autor Macedo (1996) também afirma que uma pesquisa bibliográfica é a busca de conteúdo através de livros que se associa com o problema do tema do trabalho, uma vez que, representa uma pesquisa que existe sobre os assuntos e o conhecimento de autores que se tratam do mesmo.

A pesquisa utilizada foi a qualitativa. Os autores Guehardt e Silveira apud Deslauriers (2009, p. 58) explicam que na pesquisa qualitativa: 
O cientista é ao mesmo tempo o sujeito e o objeto de suas pesquisas. O desenvolvimento da pesquisa é imprevisível. O conhecimento do pesquisador é parcial e limitado. O objetivo da amostra é de produzir informações aprofundadas e ilustrativas: seja ela pequena ou grande, o que importa é que ela seja capaz de produzir novas informações (DESLAURIERS, 2009, p. 58).

E também exploratória que segundo Marconi e Lakatos (2010) é uma pesquisa que tem como objetivo levantar problemas, com as funções de: criar hipóteses, melhorar a capacidade do tema do trabalho em relação ao seu autor e explicar novos conceitos.

\section{Resultados e Discussão}

A administração de estoque dentro das empresas é essencial, uma vez que, há uma intervenção sobre a gestão das mesmas, sendo por meio dos clientes, que podem deixar de comprar, uma vez que, optam por obter produtos nas empresas que tenham em estoque ou na gestão financeira que perdem recursos em deixar de ter um estoque, pois a partir do momento em que as organizações possuem um armazenamento de mercadorias, as empresas têm como garantia um total poder de barganha sobre as outras empresas.

A função estoque dentro das empresas é, contudo, indispensável. Segundo Martins e Alt (2009) o conhecimento dos estoques das empresas é tão antigo quanto a administração. Assim como, um processo produtivo que no final da cadeia de suprimentos criará algum vínculo para o consumidor final, o estoque é primordial e é um dos setores mais importantes dentro de uma empresa. As empresas, atualmente, buscam sempre manter vantagens em relação ao consumidor e aos seus concorrentes, com um estoque atualizado é possível atender uma demanda vasto de clientes, no momento e na quantidade desejada. Aliás, os estoques também servem para as negociações de preços com os fornecedores, muitas vezes, há promoções em compras de grandes quantidades, o que se torna um benefício para as empresas.

Além disso, as empresas adquirem vantagens competitiva contra incertezas na demanda e no tempo de entrega (isso significa que caso aja a possibilidade do fornecedor atrasar com os produtos, a garantia de a mercadoria estar em mãos do cliente é nitidamente maior, pois haverá no estoque),nas mudanças de preços (no qual, uma alta compra de produtos, minimiza o aumento de preços, pois, o estoque antigo comprado por preços antigos, terá vantagens na 
hora de elaborar o preço de venda) e na possibilidade de imprevistos(no caso de algum fornecedor entrar em férias coletivas ou em greve e a empresa ficar sem o produto para atender aos clientes, isso não vai acontecer, devido ao estoque). Atender aos clientes na hora certa com a quantidade desejada tem sido uma das principais vantagens, assim como a rapidez e a qualidade na prestação das mercadorias que declaram cada vez mais uma vantagem competitiva no mercado, afirmou Ballou (1978, apud Martins e Alt, 2009, p. 171).

Por outro lado, dentro das empresas há inúmeros tipos de estoques, que de acordo com Pozo (2004), são: estoques de matérias-primas que são os materiais que irá ser modificado para entrar no estoque de produtos acabados, estoques de materiais auxiliares que são ferramentas necessárias para a fabricação dos produtos, estoques de manutenção que é utilizada para o armazenamento de materiais que fazem parte da manutenção dos equipamentos e também do escritório, estoque intermediário que são aonde os produtos préfinalizados (aqueles que faltam alguma peça, que não tem no estoque de manutenção) e o estoque de produtos acabados que são as mercadorias que já estão fabricadas e devidamente embaladas para o processo de vendas.

Se as empresas adotarem ter um estoque, os custos serão de armazenamento e movimentação. Esses custos englobam os custos do espaço, das condições de armazenagem, como por exemplo, ambientes climatizados, movimentação interna, controles, perdas, produtos obsoletos, extravios, entre outros.

Por fim, para que o estoque ocorra de maneira eficaz Dias (2011) explica que é fundamental a competência no momento do controle de estoques, no qual, determina-se o que e quando comprar, quanto de estoque é necessário certo período de tempo, detectar os produtos com defeitos e fazer a retirada dos mesmos, receber as mercadorias e deposita-las corretamente de acordo com cada necessidade, fazer o controle de estoque e comunicar os outros colaboradores sobre o posicionamento do mesmo, informar o responsável por compras para realizar a aquisição de produtos faltosos no estoque; e conservar o balanço e o inventário frequente para a organização dos produtos em estoque. 


\section{Considerações Finais}

Nos dias de hoje, a tecnologia está cada dia mais avançada, a globalização, a inflação, a bolsa de valores e todos os recursos que fazem parte das questões financeiras sofrem constantes transformações. A administração de empresas, sendo uma área que engloba vários setores eque tem total influencia em quesito fluxo financeiro, é um setor que também passa por várias modificações. Porém, dentro da administração de empresa há a administração de materiais que contribui para a alavancagem financeira e para que isso esteja a todo o momento se maximizando.

Todavia a partir das pesquisas feitas, constata-se que com o atual e evidente crescimento industriale mundial em todos os ramos supostamente existentes, e com uma população mundial cada vez mais ocupada e com um tempo determinado para cada atividade de seu dia, o estoque se torna altamente fundamental em qualquer empresa, pois além de ser extremamente eficiente em razões de atendimento e agilidade nos processos de compra e venda, estimulatambém a economia global, quanto mais produtos comprados, mais transporte, fabricação e evidentemente mais rendimento industrial.

No entanto, um estoque exige investimentos e custos, todavia, ajuda a evitar desagradáveis situações, como o risco de diminuir a demanda dos clientes dentro das empresas. Por esse motivo as principais razões para que as empresas comecem a adotar o sistema de estocagem dos produtos são: a possibilidade de ter o material em mãos no momento em que desejar, benefícios em relação ao custo unitário e segurança contra períodos inesperados de fornecedores. As empresas precisam estar cientes de que administração de materiais é um processo que se desenvolve num tempo ativo e em um ambiente que sofre modificações em um intervalo de tempo muito curto.

Para que o estoque tenha resultados positivos dentro das empresas, é necessário que o mesmo controle, organize, saiba o que e quando comprar e então se adapte às constantes mudanças. Por isso, é preciso ter um ponto de vista de todo o processo que engloba o controle de estoques, aprendendo também, a analisar sobre cada método, assim como: compras, controle de estoques, benefícios que lhes traz, custos, tipos de estoques, entre outros. E analisar os problemas postos pela sociedade e os que apresentam-seno momento da existência dos estoques, analisar e resolvê-los de acordo com cada situação, uma vez que, a globalização e as inflações do mundo passam por determinadas mudanças e é necessário que as empresas 
saibam como resolver os problemas com cuidado, responsabilizar-se por um estoque é fácil, porém, quando se sabe o que e quando comprar. Por fim, os estoques podem ser benéficos para as empresas quando se entende sobre o assunto, já que sua única missão é oferecer para as empresas resultados satisfatórios.

\section{Referências}

BENTO, Ailton. A Importâcia da Gestão de Estoques: Estudo de Caso em uma Indústria Automobilística. Florianópolis: 2008. Disponível em:

https://repositorio.ufsc.br/xmlui/bitstream/handle/123456789/91461/261747.pdf?sequence=1 \&isAllowed $=$. Acesso em: 21/11/2016.

CARVALHO, Claudinê Jordão. Como a Gestão de Práticas de Oferta de Crédito Impacta a de Estoque. UFU: 2015. Disponível em:

http://www.scielo.br/scielo.php?script=sci_arttext\&pid=S1415-

65552015000700006\&lang=pt . Acesso em: 21/11/2016.

CERVO, Amado L. e BERVIAN, Pedro A. Metodologia Científica. $5^{\circ}$ Edição. São Paulo. Editora: Afiliada, 2002.

DIAS, Marco Aurélio P. Administração de Materiais: Princípios, Conceitos e Gestão. $6^{\circ}$ Edição. São Paulo. Editora: Atlas, 2011.

GERHARDT, Tatiana Engel e SILVEIRA, Denise Tolfo. Métodos de Pesquisa. $1^{\circ}$ Edição. Rio Grande do Sul. Editora: UFRGS, 2009.

GONÇALVES, Paulo Sérgio. Administração de Materiais. $3^{\circ}$ Edição. Rio de Janeiro. Editora: Elsevier, 2010.

IUDÍCIBUS, Sérgio de, MARTINS, Eliseu, GELBCKE, Ernesto Rubens. Manual de Contabilidade das Sociedades por Ações. 5. ed. São Paulo. Editora: Atlas, 2000.

MACEDO, Neusa Dias de. Iniciação à Pesquisa Bibliográfica: Guia do Estudante Para a Fundamentação do Trabalho de Pesquisa. $2^{\circ}$ Edição. São Paulo. Editora: Loyola, 1996.

MARCONI, Marina de Andrade e LAKATOS, Eva Maria. Fundamentos de Metodologia Científica. $7^{\circ}$ ed. São Paulo. Editora: Atlas, 2010.

MARCONI, Marina de Andrade e LAKATOS, Eva Maria. Fundamentos de Metodologia Científica. $7^{\circ}$ ed. São Paulo. Editora: Atlas, 2010.

PAURA, Glávio Leal. Fundamentos da Logística. IFMT. Curitiba, 2012. 
POZO, Hamilton. Administração de Recursos Materiais e Patrimoniais. $3^{\circ}$ Edição. São Paulo. Editora: Atlas, 2005.

VIANA, João José. Administração de Materiais: Um Enfoque Prático. $1^{\circ}$ Edição. São Paulo. Editora: Atlas, 2006.

Como citar este artigo (Formato ABNT):

AKEMI, Karina; RIBEIRO, Mariana E.O.; LAVOR, Anna A. de; SILVA, Antônio C. A. da; O Departamento de Estoque como fator influenciador na Gestão de Empresas. Id on Line Revista Multidisciplinar e de Psicologia, 2017, vol.11, n.38, p.16-27. ISSN: 1981-1179.

Recebido: 22.08 .2017

Aceito: 23.08 .2017 